\title{
Infographic: Top social media tips for sports and exercise medicine practitioners
}

Osman Hassan Ahmed, ${ }^{1,2}$ Richard Weiler, ${ }^{3,4}$ Anthony G Schneiders, ${ }^{5}$ Paul McCrory, ${ }^{6}$ John Sullivan ${ }^{7}$

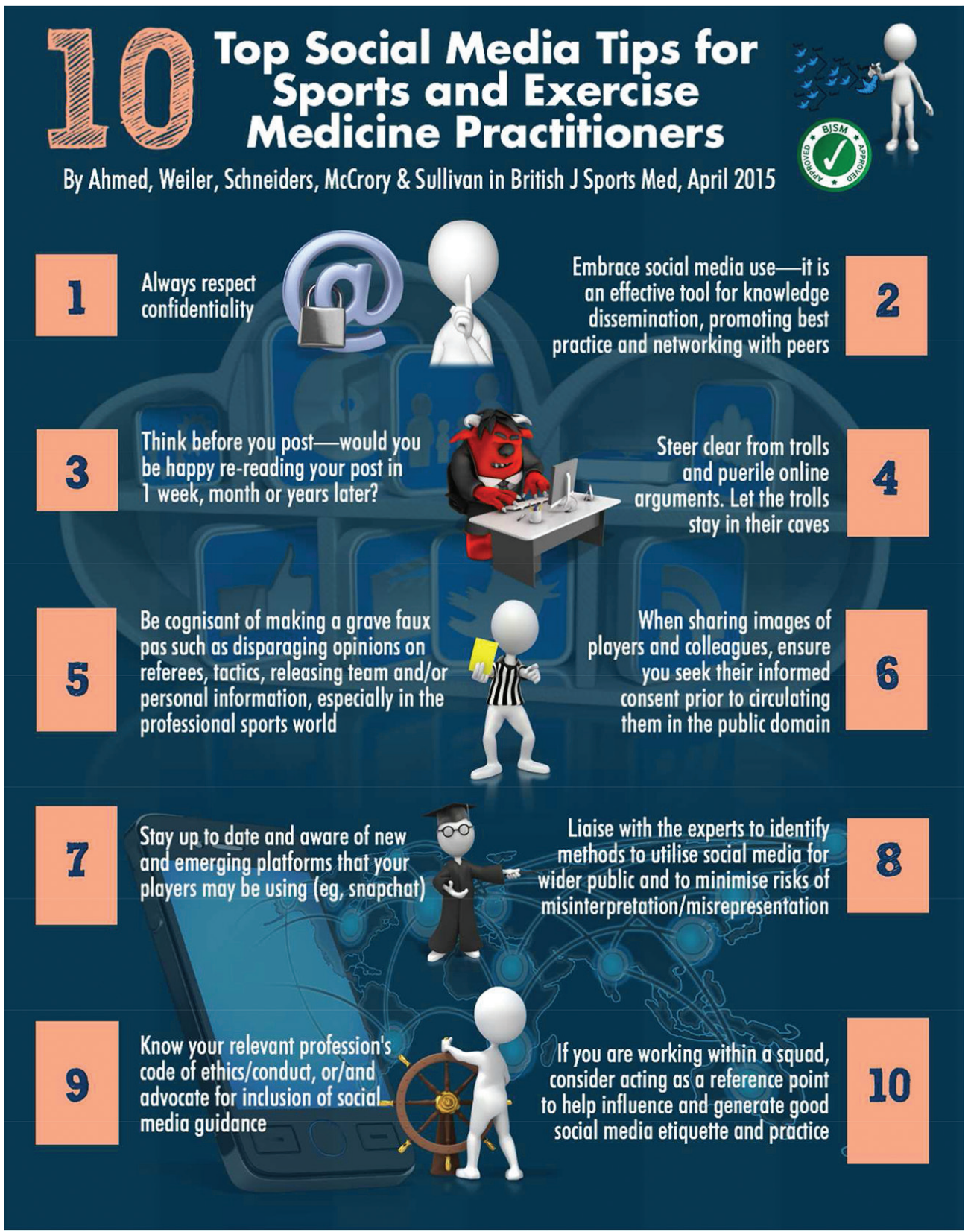

'Faculty of Health and Social Sciences, Bournemouth University, Bournemouth, UK

${ }^{2}$ The FA Centre for Disability Football Research, The Football Association, Burton-Upon-Trent, UK ${ }^{3}$ Institute of Sport, Exercise and Health, University College London Hospitals NHS Foundation Trust, London, UK

${ }^{4}$ Sport \& Exercise Medicine, Fortius Clinic, London, UK

${ }^{5}$ School of Human, Health and Social Sciences, Central Queensland University, Branyan, Australia

${ }^{6}$ The Florey Institute of Neuroscience and Mental Health, Heidelberg, Australia
${ }^{7}$ School of Physiotherapy, University of Otago, Dunedin, New Zealand

Correspondence to Dr Osman Hassan Ahmed,

Faculty of Health and Social Sciences, Bournemouth University, Bournemouth BH1 3LT, UK; osman.hassan. ahmed@gmail.com

Competing interests None declared.

Provenance and peer review Commissioned; externally peer reviewed.

(C) Article author(s) (or their employer(s) unless otherwise stated in the text of the article) 2017. All rights reserved. No commercial use is permitted unless otherwise expressly granted.

To cite Ahmed OH, Weiler R, Schneiders AG, et al Published Online First: [please include Day Month Year]. doi:10.1136/bjsports-2017-097513

\section{Accepted 12 March 2017}

Br J Sports Med 2017:0:1

doi:10.1136/bjsports-2017-097513 